\title{
Gary Victor, Quand le jour cède à la nuit
}

\section{Emanuela Cacchioli}

\section{(2) OpenEdition}

\section{Journals}

\section{Edizione digitale}

URL: https://journals.openedition.org/studifrancesi/3253

DOI: 10.4000/studifrancesi.3253

ISSN: 2421-5856

\section{Editore}

Rosenberg \& Sellier

\section{Edizione cartacea}

Data di pubblicazione: 1 juillet 2013

Paginazione: 499-500

ISSN: 0039-2944

\section{Notizia bibliografica digitale}

Emanuela Cacchioli, «Gary Victor, Quand le jour cède à la nuit», Studi Francesi [Online], 170 (LVII | II) |

2013, online dal 30 novembre 2015, consultato il 02 février 2023. URL: http://

journals.openedition.org/studifrancesi/3253 ; DOI: https://doi.org/10.4000/studifrancesi.3253

\section{Questo documento è stato generato automaticamente il 2 février 2023.}

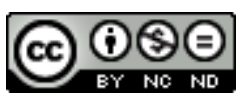

Creative Commons - Attribuzione - Non commerciale - Non opere derivate 4.0 Internazionale - CC BY NC-ND 4.0

https://creativecommons.org/licenses/by-nc-nd/4.0/ 


\title{
Gary Victor, Quand le jour cède à la nuit
}

\author{
Emanuela Cacchioli
}

\section{NOTIZIA}

GARY VICTOR, Quand le jour cède à la nuit, La Roque d'Anthéron, Vents d'ailleurs, 2012, pp.

128.

1 L'ultima fatica letteraria di Gary Victor costituisce l'incipit del suo percorso di scrittore. L'autore ha, infatti, raccolto in un unico volume undici novelle scritte all'epoca dei suoi esordi e già pubblicate tra il 1977 e il 1987 su alcuni quotidiani di Port-au-Prince. La decisione di riproporre al pubblico questi testi si è imposta, dopo trent'anni, per recuperare un materiale che era andato perduto e dimenticato. Si tratta di novelle che già recano lo stile e le tematiche poi sviluppate da Gary Victor nei suoi romanzi più celebri. Ovviamente il genere della novella richiede una maggiore acutezza da parte dello scrittore che è obbligato a condensare in poche pagine una storia eccezionale attraverso una narrazione netta, incisiva. Eppure in questi brevi testi è già possibile rintracciare quell'atmosfera di violenza e di assurdità che caratterizza l'universo di Victor. La dimensione sociale è centrale e viene affrontata sotto varie angolazioni: dall'esistenza di privazioni e dalla povertà che attanaglia la maggior parte della popolazione alla corruzione e all'atteggiamento di indifferenza della classe politica e dirigente nei confronti della massa. I personaggi, in questo contesto, superano il ruolo di individui e assumono le sembianze di tipi umani in grado di esemplificare tutta una categoria di esseri viventi. La maggior parte di loro appartiene alla realtà haitiana, ma non mancano le incursioni in altri luoghi della Terra (e addirittura dell'Universo), a significare che tutta l'umanità è accomunata dalle stesse problematiche e vicissitudini. Il lettore ritrova anche quell'inquietudine perenne che caratterizza la produzione romanzesca di Gary Victor. Esistono figure positive che paiono risollevare le sorti dell'umanità per un momento. Si tratta, tuttavia, solo di brevi istanti che lasciano poi il posto alla delusione e all'oscurità del quotidiano. Occorre anche menzionare la 
presenza dell'ironia, sintomo di una duplicità dell'esistenza, che conduce spesso ad una risata amara. $\mathrm{O}$ addirittura alla schizofrenia. Accade di frequente che i personaggi, sottoposti alla durezza della realtà, rivelino i loro lati più nascosti e quei tic psichici che normalmente passano inosservati. Tale aspetto è messo in luce anche da Yves CHEMLA, autore della Préface (pp. 7-11) che introduce la raccolta. Lo studioso sottolinea come le novelle di Gary Victor abbiano la facoltà di lasciare intravedere dei mondi nascosti, degli spazi paralleli insospettati e abitati dall'orrore. Il nostro sguardo si rassegna alla banalità dell'esistenza e lascia che l'opacità impedisca a queste epifanie di manifestarsi. Il testo di Victor, al contrario, stimola l'immaginazione e rende palese il Male latente che governa la società. E la popolazione, votata all'istinto di sopravvivenza, mette in atto tutta una serie di strategie che le assicurano un'opposizione attiva o una resistenza interiore. Proprio quest'ultima garantisce alla coscienza di persistere di fronte alla decomposizione del mondo circostante. Gary Victor ci descrive, dunque, un male smisurato e onnipresente, ma ce ne fornisce un'immagine che è lontana dalla rappresentazione a cui ci ha comunemente abituati la cultura europea. Il Male, infatti, non viene ridotto ad un essere diabolico o ad un peccato originale. Esso si manifesta concretamente nello spazio e si riconduce allo sfruttamento senza limiti e alla logica del potere e del denaro. Un universo cinico dal quale l'uomo haitiano riesce a fuggire solo grazie all'immaginazione: un dono che, a differenza di quanto si crede, non è sopito, ma si innesca spontaneamente ogni qualvolta se ne presenti la possibilità. Si produce, in questo modo, una realtà simbolica che scaturisce anche dal contesto storico in cui le novelle sono state scritte: Gary ha prodotto i testi all'epoca della dittatura e doveva sottostare alle imposizioni della censura. Le undici novelle inserite nella raccolta sono: Quand la planète t'appartiendra (pp. 13-20), Ma femme-rêve de la terrasse (pp. 21-25), Qui êtes-vous, Monsieur? (pp. 27-32), La dernière pluie (pp. 33-38), Univers capital (pp. 39-52), Le phare d'Astaroth (pp. 53-61), Détritus Ballet (pp. 63-71), La pêche infernale du Mardi gras (pp. 73-83), Promesses d'avenir, ou les super branchés (pp. 85-93), L'utopie de l'envers du temps (pp. 95-112), Fragments d'azur au-dessus des ténèbres (pp. 113-123). Per facilitare la comprensione al lettore, è stato aggiunto un breve glossario - Lexique (p. 125) - in cui vengono chiariti alcuni riferimenti letterari, storici e culturali che compaiono nelle novelle. 